\title{
Discussion on fire proof design and application in power system substation
}

\author{
Shi Zhongzhi, Su Zongyu, Sun Baoquan \\ Benxi Power Supply Company of National Grid Liaoning Electric Power Co., Ltd. \\ bxwl_650928@126.com
}

Keywords: fire proof; seal; control

\begin{abstract}
Substation plays an important role in the power transmission system for it is a connecting link between the preceding and the following, and fire proof is an important link related to whether substation runs safely. In unexpected events, the normal operation of fire proof system is very important in achieving the suppression and extinguishment of early fire.
\end{abstract}

\section{Introduction}

With the development of industry and the improvement of people's living standards, the load of the substation is increasing. Therefore, the fire accidents caused by the electric circuit are increasing year by year, which has caused great loss to the country and people. How can the occurrence of fire in the substation be prevented? In order to prevent fire, the fire resistance of the substation is extremely important.

\section{Analysis of fire in the substation}

(1) Most substations of $220 \mathrm{kV}$ and above are on the outskirts of the city and the suburbs, and overhead ingoing and outgoing lines are mostly used, while power cables are few;

(2) Although $220 \mathrm{kV}$ terminal stations and the substations at lower voltage level are directly connected with the users, the power cables, with few quantities, in the substation are not long, and the layout is scattered because the vast majority of substations are overhead lines. At present, the total length of $66 \mathrm{kV}$ cables in the company is more than $500 \mathrm{~km}$ and some substations use all outlet cables, which are dense in the cable trench, but generally not more than 30 .

(3) There are a large number of cables in the substation, and the longest are control, measurement and signal cables. Control cable bears the pulse load, and in normal operation, the load rate is very low; to ensure measurement accuracy, measurement cable has a large margin on the section; signal cable is basically in two extreme state (conduction, opening), and in normal operation, about over half of the signal cables are only with voltage but without current flow. From the foregoing, the heat productivity of these cables is very small, so there is no overheat problem, and the probability of fire caused by these cables is almost zero;

(4) The vast majority of $66 \mathrm{kV}$ cables in the substation are single laid separately, so even there is short circuit fire, it will not affect other cables and it is unlikely to have big area fire.

\section{Fire proof system and alarm system in the substation}

The fire proof system in the substation is composed of the alarm system, fire proof system and fire seal.

The alarm system in the substation is composed of the detection system and the linkage control system.

The detection system is composed of a smoke detector, a temperature sensor, a composite smoke temperature detector, a combustible gas detector, an infrared detector, a temperature sensing cable, a signal input module and a manual alarm button. Different types of fire detection are realized by setting up different detectors for different protected areas. 


\section{Detector selection.}

Smoke detectors are used for fire alarm in general buildings. Infrared detectors and composite smoke detectors and temperature sensing detectors are mainly for the buildings with the beams higher than 300mm, which are generally used in GIS rooms. Temperature sensing cables, which are mainly used for cables on the cable bridge, are generally laid on the top of the cables in the way of sine wave. Combustible gas detectors, which are to prevent the occurrence of leakage of natural gas, coal gas, and the combustible gas which may go into the fire proof system of the substation along the cable tunnel, are set up in the inlet end of the cable tunnel.

Detection of the transformer room: because the transformer room is generally higher than 8 meters, and its highest point can reach 14 meters, it can not meet the standard requirements by using the traditional detection method. Therefore, the signals provided by the relay protection in the substation and the temperature sensing cables are used as the fire detection signal of the transformer.

\section{Linkage control.}

Fire alarm signals in the detection system are collected, and fire and sound signals are emitted. When meeting the conditions of fire proof, fire related proof equipments are automatically or manually started, corresponding fire proof valve is shut down, and the non fire proof power is cut off. The system is composed of the alarm host, the operating disk for control, and standby power supply.

\section{System function.}

The system has the function of collecting the fire proof signals of the building and electrical equipment in the whole substation. And according to the fire condition, fire fighting equipment is started, fire fighting valve is shut off, ventilation system in the cable tunnel is turned on, the alarm bell or the audible and visual alarm is actuated, the fire alarm is sounded, and the fire signal will be uploaded to the central substation and dispatching center according to the requirements.

\section{Fire extinguishing system}

The fire extinguishing system in the substation is divided into water spray extinguishing system, gas fire extinguishing system and portable fire extinguishing system. For the outdoor main transformer substation, water spray fire extinguishing system is adopted; for the indoor main transformer, capacitor room, cable interlayer and grounding transformer, gas extinguishing system is adopted.

\section{Water spray fire extinguishing system.}

Water spray extinguishing system is composed of spray nozzle, water supply network, the deluge valve (or electric valve), and pump room.

The water spray fire extinguishing equipment fights the fire by using the cooling effect of the water mist, stifling effect of the vapor of the water mist, the impact force of the water mist as well as the water film formed on the surface of inflamer by the water mist. Its fire extinguishing principle is as follows:

\section{(1) The cooling effect of water mist:}

Water spray fire extinguishing equipment is characterized by small particle of water mist, and small spray area. Therefore, the contact area of water mist in the combustion area and around is tens of thousands of times larger than that of the stream water of water stream nozzle, giving full play of cooling effect on combustion zone and explosive materials, so that the surface temperature of combustion zone or the burning objects decreases rapidly, and when the temperature of the burning objects is below the ignition point, flame is extinguished and burning stops.

\section{(2) The stifling effect of water mist:}

When the water mist is sprayed into the combustion zone, the temperature of the water mist rises instantly, and the small particle of the water mist is quickly vaporized. In the vaporization process, it absorbs a lot of heat, so that the temperature of the combustion zone further decreases, and at the same time, a large amount of vapor fills the combustion zone. The increase of the 
inflammable vapor leads to the decline of concentration of oxygen in the combustion zone, so that oxygen is seriously deprived in the combustion space, and the flame is extinguished.

\section{(3) The coverage of the water film:}

The diffusion area of spray stream is large, so that in a short period of time, water film forms on the surface of the burning objects, which plays a role in isolating the air and cooling the objects, making the combustible material difficult to continue to burn.

\section{(4) The impact and emulsification:}

The initial velocity of the spray stream is very high, and energetic. When it is mixed with the non water soluble liquid, especially with oil surface, the mixture of "oil and water", "oil in water" or "oil on water" forms on the liquid level of the oil due to the impact. The mixture is in a form of milk, floating on the surface of the combustible liquid. Although the production and disappearance of the emulsion is instantaneous, the emulsion is feathered of continuity because of the continuous spray stream and since it is inflammable, it plays a role in fire resistance.

\section{(5) Dilution:}

Spray water can be a good combination with water soluble liquid, so that the water soluble liquid is diluted, and the concentration decreases. When it decreases to a certain concentration, the fire proof system of the $220 \mathrm{kV}$ substation will not continue to burn.

In the actual fire disaster, the fire extinguishing effect of the spray water often plays a comprehensive role, that is, it may play an important role in some fixed positions such as one or two elements, while other fire proof systems are auxiliary.

\section{Spray nozzle.}

The layout of the spray nozzle is divided into three layers, and arranged according to the appearance of the distribution transformer. Top layer covers the top of the transformer, the middle and lower layers cover the side of the transformer, and the other two points cover the oil conservator. The intensity of water spray is greater than $20 \mathrm{~L} / \mathrm{sec} . \mathrm{m}^{2}$, and the particle diameter of the water mist is less than $0.7 \mathrm{~mm}$. The water mist has a far spray distance and a large impact force, which ensures that the spray system has a good cooling effect in fire extinguishing.

\section{Water supply network.}

The water supply network is composed of a dry and a wet system. The dry system, which is from the deluge valve to network around the main transformer, usually does not have water, and the wet system, which is from the deluge valve to the pump, usually has $3 \mathrm{~kg}$ of water, to ensure the rapid response of the system after startup and the response time is less than 45 seconds. The water pressure of each nozzle is guaranteed basically equal by using annular pipeline to achieve the best spray effect. All the cycle pipes use hot galvanized steel pipes, to improve the ability of corrosion resistance, and the wet system uses heat preservation measures to improve the system's ability of freeze resistance.

In the water pump group, one pump is used and the other is a standby to ensure the reliable operation of the system in any case. The water pump group is started in automatic sequence in the control cabinet, and if there is failure, the standby water pump is automatically input, and simultaneously manual start function of the water pump in the urgent situation is turned on.

Gas fire extinguishing system is composed of a nozzle, a pipe network, a cylinder, a fire extinguishing agent and a cylinder plate. According to the different requirements, the system can be divided into 2-8 fire proof districts. The system uses the method of total flooding combination distribution and plans the consumption based on the largest fire proof area, which is able to meet the fire fighting requirements, and reduce the system cost.

\section{Protection measures in the substation}

(1) It adopts the gas insulated switchgear (GIS), using SF6 gas as insulation between interphase and the charged parts and the grounding parts. The three phases are arranged by the equilateral triangle and the geometrical size of interphase is very small, the charged equipment is sealed in the grounded alloy cylinder and the outer electric field and magnetic field are almost zero. 
(2) The layout of the substation is optimized to minimize the impact on the environment as much as possible.

(3) The urban substations can be built into an indoor substation.

(4) The substation is beautified. A green barrier is arranged around the substation, and the appearance of the substation is coordinated with the surrounding environment.

(5) Transformer oil inside the transformer is for insulation and cooling, and owing to the high flash point of current transformer oil, there is strict fire proof requirement in the substation by the state so substation is rarely on fire. And the state has strict requirements on the fire resistance of the substation near residential buildings. For example, the fire proof facilities within the substation need to be equipped with fire proof automatic alarm system, water spray fire extinguishing system, Heptafluoropropane gas fire extinguishing system, and fire hydrant system according to the layout and fire proof requirements of various electrical equipment rooms, so as to meet the requirements of "dominant in prevention, and combining fire prevention with fire proof ".

\section{Reference}

[1] Ministry of Public Security of the People’s Republic of China GB 2006, 50016---2006 Fire proof code of building design [s], China Planning Press, 2006

[2] Ministry of Public Security of the People's Republic of China GB 50229--- 2006 fire proof design code of thermal power plant and substation[s]. China Planning Press 2006

[3] Ministry of Public Security of the People’s Republic of China GB 50219 --- 95 water spray fire proof design code of water spray[s]. China Planning Press, 1995

[4] The second research and design Institute of nuclear industry. Water supply and drainage of buildings (Second Edition) [M] . China Building Industry Press, 2001:178 --- 194

[5] China State Grid Corp. Safety risk assessment of power supply enterprises [M]. Beijing: China Electric Power Press.2009. 